\title{
PENGARUH PEMAHAMAN KURIKULUM 2013 DAN INTEGRITAS GURU TERHADAP KINERJA GURU-GURU SD KATOLIK DI MANADO
}

\author{
Kosmas Sobon $^{1}$, Jelvi Monica Mangundap ${ }^{2}$, Stief Walewangko ${ }^{3}$ \\ ${ }^{1,2,3}$ Universitas Katolik De La Salle Manado
}

\begin{abstract}
The purpose of this research is to evaluate and analyze the understanding of the curriculum 2013 and integration on the performance of Catholic elementary school teachers in Manado City. The total of samples are 76 respondents in 11 Catholic Primary Schools. This research is in June to July 2019. The method of the research is quantitative approach by survey methods. The results showed that (1) There is a positive influence of the understanding of the curriculum 2013 on the performance of Catholic elementary school teachers in Manado City. The effect of understanding of the curriculum 2013 on teacher performance was relatively low that is $39.1 \%$ with a significance level of $0.000 \leq$ from $\alpha=0.05$. While the results of the hypothesis test knowledge variable with the test shows the fact that $t$-count $=6.889 \geq(t$-tab) $=1.992$. (2) There is effect of teacher's integration on the performance of Catholic elementary school teachers with the results of the determination of percentage, $8.2 \%$ and a significance level of $0.012 \leq$ from $\alpha=0.05$;

(3) There is a effect of curriculum 2013 and integration simultaneously on the performance of Catholic elementary school teachers, $37.5 \%$ with a significance level of $0,000 \leq$ from $\alpha=0.05$
\end{abstract}

Keyword: Curriculum 2013, Integration, the Performance of Teacher

\begin{abstract}
Abstrak: Tujuan dari penelitian ini adalah untuk memahami dan menganalisis pengaruh pemahaman kurikulum 2013 dan integritas terhadap kinerja guru-guru SD Katolik di Kota Manado. Jumlah sampel yang digunakan adalah 76 responden yang tersebar pada 11 Sekolah Dasar Katolik yang ada di Kota Manado. Waktu pelaksanaan penelitian bulan Juni sampai dengan Juli 2019. Metode penelitian adalah pendekatan kuantitatif dengan metode survey. Hasil penelitian menunjukkan bahwa (1) Terdapat pengaruh positif faktor pemahaman kurikulum 2013 terhadap kinerja guru SD Katolik di Kota Manado. Pengaruh pemahaman kurikulum 2013 terhadap kinerja guru tergolong masih rendah yakni 39,1\% dengan tingkat signifikansi $0,000 \leq$ dari $\alpha=0,05$. Sedangkan hasil pengujian hipotesis variabel pengetahuan dengan $t$ test menunjukkan bahwa ternyata yakni $t_{\text {hitung }}=$ $6.889 \geq\left(\mathrm{t}_{\mathrm{tab}}\right)=1.992 ;(2)$ Terdapat pengaruh integritas terhadap kinerja guru SD Katolik di Kota Manado dengan hasil prosentasi determinasi 8,2\% dan tingkat signifikansi sebesar $0,012 \leq$ dari $\alpha=0,05$; (3) Terdapat pula pengaruh pemahaman kurikulum 2013 dan integritas secara bersama-sama terhadap kinerja guru SD Katolik di Kota Manado yakni sebesar 37,5\% dengan tingkat signifikansi $0,000 \leq$ dari $\alpha=0,05$.
\end{abstract}

Kata Kunci: Kurikulum 2013, Integritas, Kinerja Guru

\footnotetext{
'Universitas Katolik De La Salle Manado, Email: ksobon国unikadelasalle.ac.id

${ }^{2}$ Universitas Katalik De La Salle Manado, Email: imangundap国unikadelasalle.ac.id

${ }^{3}$ Universitas Katalik De La Salle Manada, Email: swalewangka回unikadelasalle.ac.id
} 


\section{PENDAHULUAN}

Guru merupakan merupakan suatu profesi yang memerlukan keahlian khusus keguruan dan pengajaran. Kualitas seorang guru dapat dilihat dari kinerja yang telah dilakukannya. Artinya, kinerja guru mempunyai peran penting dalam pencapaian tujuan sekolah dan kualitas belajar siswa. Secara sederhana kinerja berarti sesuatu yang dicapai, hasil atau luaran dari sebuah proses. Untuk lebih jelas Mulyasa (dalam Haslina, dkk, 2017, hlm. 212) menegaskan "kinerja adalah untuk kerja seseorang yang ditunjukkan dalam penampilan, perbuatan dan prestasi ker janya sebagai akumulasi dari pengetahuan, keterampilan, nilai dan sikap yang telah dimilikinya." Kinerja guru berhubungan hasil kerja yang dicapai guru dalam melaksanakan tugas pokok, fungsi dan tanggungjawabnya dalam mengelola dan mengatur sekolah yang di pimpinnya.

Sekarang ini masalah kinerja guru menjadi sorotan berbagai pihak, baik dari pemerintah, yayasan sekolah, masyarakat maupun dari pihak stakeholders. Misalnya penghargaan pemerintah pusat terhadap peningkatan guru -guru SD lewat tunjangan sertifikasi diduga tidak mempengaruhi kinerja guru. Ada kecenderungan dana sertifikasi digunakan bukan untuk pengembangan kinerja guru, melainkan untuk kepentingan di luar profesinya sebagai guru. Kenyataan ini menjadi sebuah contoh kemunduran akan peningkatan kinerja guru.

Salah satu indikator yang diduga dapat meningkatkan kinerja guru SD adalah tingkat pemahaman kurikulum. Pemerintah lewat Kementerian Pendidikan Dasar dan Menengah tahun ajaran 2018/2019 ini menganjurkan kepada seluruh sekolah dasar dan sekolah menengah untuk menggunakan kurikulum 2013 bagi semua kelas. Kebijakan ini menjadi sebuah tantangan yang besar bagi beberapa satuan pendidikan (sekolah) yang belum up to date dengan masih menggunakan kurikulum KTSP. Namun bagi sekolah yang sudah beradaptasi dengan kurikulum 2013 beberapa tahun terakhir ini menjadi bukan sesuatu yang baru.

Di lain pihak, revolusi mental yang dicita -citakan pemerintah bagi masyarakat khusus tenaga pendidik menjadi hal yang sangat penting demi peningkatan kinerja seorang guru SD. Integritas guru menjadi indikator utama bagi proses pembentukan revolusi mental. Guru yang profesional adalah guru berintegritas. Ciri khas guru yang berintegritas memiliki sikap kejujuran, kredibilitas dan konsistensi dengan nilai -nilai ke dalam tindakan. Malingkas (2018, hlm. 9) menegaskan bahwa integritas personal (indididual) bisa dilihat dari kejujuran, komitmen dan konsistensi yang dilakukan setiap orang (quality of being honest and upright). Singkatnya, guru yang punya integritas adalah guru yang mampu menunjukkan kesesuaian antara yang batiniah dan lahiriah.

Hasil observasi ditemukan masih banyak guru SD Katolik di Kota Manado yang belum memahami dengan benar isi dan struktur utama kurikulum 2013, namun kurikulum 2013 segera diimplementasikan tahun ini. Realitas ini menjadi sebuah masalah utama bagi peningkatan kinerja guru SD. Maka, pentinglah membuat penelitian untuk mengukur dan menganalisis tingkat pemahaman kurikulum 2013 dari guru guru SD Katolik di Kota Manado. Begitupun dengan integritas guru akhirakhir ini sangat menurun khususnya pada guru SD Katolik misalnya adanya ketidakjujuran penilaian hasil belajar, pelaporan keuangan sekolah, jarang masuk, mengajar tanpa persiapan, pungutan liar, kehilangan respek dari siswa karena perilaku yang tidak baik dalam kehidupan masyarakat. Realitas ini mendorong peneliti membuat sebuah penelitian tentang integritas guru SD Katolik di Kota Manado apabila dihubungkan dengan kinerja mereka di sekolah. 
Untuk itu, tanpa mengabaikan berbagai faktor yang mempengaru hi kinerja guru, maka peneliti tertarik untuk meneliti tentang: "Pengaruh pemahaman kurikulum 2013 dan integritas guru terhadap kinerja guru-guru SD Katolik di Kota Manado." Adapun rumusan masalah dari penelitian ini adalah: (1) Apakah terdapat pengaruh pemahaman kurikulum 2013 terhadap kinerja guruguru SD Katolik di Kota Manado? (2) Apakah terdapat pengaruh integritas terhadap kinerja guru-guru SD Katolik di Kota Manado? (3) Apakah terdapat pengaruh pemahaman kurikulum 2013 dan integritas secara bersama-sama terhadap kinerja guru-guru SD Katolik di Kota Manado?

\section{Kinerja Guru}

Kata kinerja adalah terjemahan dari "performance" yang menurut The Concise Oxford Dictionary, of Current English (Armstrong, 2006, hlm. 7) berasal dari akar kata "to perform" dengan beberapa pengertian, yaitu : Melakukan, menjalankan, melaksanakan (to do or carry out, execute); Memenuhi atau melaksanakan kewajiban suatu niat atau nasar (to discharge of fulfill, as vow); Melaksanakan atau menyempurnakan tanggung jawab (to execute or complete an understaking ); Melakukan sesuatu yang diharapkan oleh seseorang atau mesin (to do what is expected of a person machine ). Koerselman (2013) menegaskan bahwa kinerja adalah kemampuan diri sendiri untuk melakukan atau menyelesaikan pekerjaan.

Kinerja guru merupakan kemampuan dan keberhasilan guru dalam melaksanakan tugas -tugas pembelajaran. Menurut Sedarmayanti (dalam Supardi, 2013, hlm. 19) bahwa "kinerja guru dipengaruhi oleh berbagai faktor. Faktor-faktor yang mempengaruhi kinerja antara lain: (1) sikap mental (motivasi kerja), disiplin kerja, etika kerja); (2) pendidikan; (3) keterampilan; (4) manajemen kepemimpinan; tingkat penghasilan; (6) gaji dan kesehatan; (7) jaminan sosial; (8) iklim kerja; (9) sarana dan prasanaran; (10) teknologi; (11) kesempatan berprestasi."

Bagi Sedarmayanti, kesebelas faktor tersebut yang mendukung rendah atau tingginya kinerja seorang guru di sekolah. Menurut Mangkunegara (dalam Ahmad, 2018, hlm. 201), faktor yang mempengaruhi kinerja guru adalah faktor kemampuan (ability) dan faktor motivasi (motivition). Pertama, setiap guru memiliki kemampuan potensi (IQ) dan kemampuan reality. Guru yang memiliki latar belakang Pendidikan yang tinggi dan sesuai dengan bidanya akan terampil mengerjakan pekerjaan sehari-hari, maka ia akan lebih mudah mencapai kinerja yang diharapkan. Kedua, setiap guru memiliki motivasi guna menghadapi situasi kerja yang ada. Motivasi merupakan kondisi yang menggerakkan seseorang yang terarah untuk mencapai tujuan pendidikan. Karena motivasi itu sendiri merupakan gejala jiwa yang dapat mendorong manusia untuk berbuat sesuatu keinginan dan kebutuhan.

Hal yang serupa diungkapkan oleh Uno \& Lamatenggo (dalam Rasto, 2016, hlm. 65) bahwa Kinerja seseorang (termasuk guru) dapat diukur melalui lima indikator berikut: (1) Kualitas kerja. Indikator ini berkaitan dengan kualitas kerja guru dalam menguasai seagala sesuatu berkaitan dengan persiapan perencanaan program pembelajaran dan penerapan hasil penelitian dalam pembelajaran di kelas. (2) Kecepatan/ketetapan kerja. Indikator ini berkaitan dengan ketepatan kerja guru dalam menyesuaikan materi ajar dengan karakteristik yang dimiliki peserta didik dan penyelesaian program pengajaran sesuai dengan kalender akademik. (3) Inisiatif dalam kerja. Indikator ini berkaitan dengan inisiatif guru dalam penggunaan model pembelajaran yang variatif sesuai materi pelajaran dan penggunaan berbagai inventaris sekolah dengan bijak. (4) Kemampuan kerja. 
Indikator ini berkaitan dengan kemampuan guru dalam memimpin keadaan kelas agar tetap kondusif, pengelolaan kegiatan belajar mengajar, dan penilaian hasil belajar peserta didik; (5) Komunikasi. Indikator ini berkaitan dengan komunikasi yang dilakukan guru dalam proses layanan bimbingan belajar dengan siswa yang kurang mampu mengikuti pembelajaran dan terbuka dalam menerima masukan untuk perbaikan pembelajaran. Dengan demikian dapat simpulkan bahwa kinerja guru merupakan kemampuan yang dilhasilkan oleh seorang guru dalam menjalankan tugas-tugasnya.

\section{Integritas}

Secara sederhana integritas adalah konsistensi dan keteguhan yang tak tergoyahkan dalam menjunjung tinggi nilai-nilai luhur dan keyakinan. Integritas adalah suatu konsep yang menunjuk konsistensi antara tindakan dengan nilai dan prinsip. Integritas menjadi karakter kunci bagi seorang guru. Seorang guru yang mempunyai integritas akan mendapatkan kepercayaan (trust) dari orang lain seperti sesama guru, siswa dan masyarakat. Guru yang berintegritas dipercayai karena apa yang menjadi ucapannya juga menjadi tindakannya.

Beberapa faktor yang mendukung dan memperkuat integritas dimana semua pelaku (actor) berkomitmen a) selfmotivation and drive, b) moral courage and assertiveness, c) honesty, d) consistency e) commitment, f) diligence, $g$ ) self -discipline, $g$ ) responsibility h) trustworthiness, i) fairness (Barnard, A, et al, 2008, hlm. 4049). Selanjutnya seseorang (guru) yang didorong memiliki integritas yang kuat ditandai dengan ciri-ciri, (a) dapat dipercaya; (b) konsisten; (c) komitmen; (d) bertanggungjawab; (e) memiliki kecerdasan emosi.

Uraian tersebut menegaskan bahwa integritas guru terletak pada komitmen (commitment), konsisten (consistenst) dan kejujuran, menjaga diri dan lingkungan kerja agar tetap bersih dan terorganisir, tetap fokus, kelilingi diri dengan oran $g$ yang berperilaku baik yang didukung dengan aturan, nilai dan norma yang sudah disepakati. Jadi, integritas sebenarnya menunjuk pada konsistensi antara tindakan dengan nilai dan prinsip. Guru yang berintegritas selalu dipercaya karena apa yang menjadi ucapannya juga menjadi tindakannya. Adapun beberapa indikator yang menunjukkan seorang guru memiliki integritas adalah: kejujuran, konsisten, bertanggung jawab dan memiliki komitmen yang tinggi.

\section{Kurikulum 2013}

Salah satu aspek yang harus dikuasai oleh seorang guru untuk menunjang kinerjanya adalah penguasaan terhadap kurikulum. Menurut Prent, Webster, dan Sabda yang dikutip oleh Supardi (2013, hlm. 141) secara etimologis istilah curriculum berasal dari Bahasa Latin yakni "curro" atau "currere" yang berarti perlombaan, gelanggang. Namun dalam dunia pendidikan dapat diartikan sebagai sejumlah mata pelajaran yang harus diselesaikan peserta didik di sekolah atau perguruan tinggi. Namun dalam arti luas, kurikulum berarti aktivitas apa saja yang dilakukan oleh sekolah dalam rangka mempengaruhi peserta didik dalam belajar untuk mencapai suatu tujuan, termasuk kegiatan pembelajaran, mengatur strategi pembelajaran, cara mengevaluasi program pengembangan dan sebagainya (Nurdin dan Masyirudin, 2002, hlm. 34). Selanjutnya Bobbit (dalam Haslina, dkk, 2017, hlm. 201) menjelaskan bahwa curriculum as an idea, has its roots in the Latin word for race-course, explaining the curriculum as the course of deeds and experiences thought whics children bec ome the adult they should be, for success in adult society. Artinya kurikulum berarti a plan for learning.

Sedangkan yang dimaksud dengan kurikulum 2013 adalah model kurikulum 
yang menggantikan kurikulum KTSP (Kurikulum Tingkat Satuan Pembelajaran) yang pertama kali diimplemantasikan pada tahuan ajaran 2013/2014 di Indonesia. Ada perbedaan yang mendasar antara kurikulum KTSP dan kurikulum yang baru yang sering disebut K-2013. Perubahan kurikulum ini berdasarkan peraturan Menteri Pendidikan dan Kebudayaan Nomor 69 Tahun 2013. Ada beberapa perubahan adanya kurikulum 2013 yakni: pertama: pola pembelajaran berpusat pada guru (teacher's centered) berubah menjadi pembelajaran berpusat pada siswa (student's centered). Kedua, pola pembelajaran satu arah (guru-peserta didik) menjadi pembelajaran interaktif (guru - peserta didik - masyarakat lingkungan alam dan sumber/media belajar lainnya). Ketiga, pola pembelajaran terisolasi menjadi pola pembelajaran berbasis jaringan artinya dapat menimba ilmu dari siapa saja dan dimana saj a; keempat, pola pembelajaran pasif menjadi pola pembelajaran aktif dan kritis; kelima, pola pembelajaran sendiri menjadi kelompok/tim; keenam, pola pembelajaran tunggal menjadi pola pembelajaran multimedia; ketujuh, pola pembelajaran berbasis massal menj adi pola pembelajaran berbasis keutuhan (user); dan kedelapan, pola pembelajaran ilmu pengetahuan tunggal (monodisciplin) menjadi pembelajaran berbasis jamak (multidiscipline).

\section{METODOLOGI PENELITIAN}

Penelitian ini menggunakan pendekatan kuantitatif. Metode penelitian yang digunakan adalah metode penelitian survei. Penelitian diselenggarakan di Sekolah-Sekolah SD Katolik yang ada di Kota Manado. Adapun waktu penelitian dilaksanakan pada bulan Juni sampai dengan Juli 2019. Populasi dalam penelitian ini adalah guru PNS dan Non PNS yang ada dalam lingkungan SD Katolik di Kota Manado Propinsi Sulawesi Utara. Sedangkan jumlah sampel yang digunakan adalah 76 guru yang tersebar dalam 11 sekolah. Pengembangan instrumen melalui beberapa tahapan, yaitu (1) melakukan kajian terhadap teori-teori dari variabel yang digunakan, (2) menyusun kisi-kisi instrumen, menyusun butir pertanyaan, (4) melakukan uji coba instrumen, (5) melakukan analisis butir pertanyaan, perhitungan validitas dan realibilitas instrumen penelitian dan (6) memilih pertanyaan yang lolos pengujian sebagai kuesioner penelitian.

\section{HASIL PENELITIAN DAN PEMBAHASAN}

\section{a. Deskripsi Data Hasil Penelitian}

Deskripsi umum dari data hasil penelitian yang mencakup variabelvariabel penelitian. Hal ini sangat penting karena dasar dalam pembahasan dan penafsiran lebih lanjut. Penyajian data penelitian dari masing-masing variabel menggunakan program SPSS 25. Di bawah ini merupakan hasil deskripsi terhadap masing-masing variabel tersebut.

Jumlah angka skor untuk variabel kinerja guru (Y) berada dalam rentang 119 hingga 173. Berdasarkan data yang diperoleh dalam penelitian kemudian diolah secara statistik dan diperoleh hasil, yakni jumlah keseluruhan $\left(\sum Y\right)=11.800$, nilai rata-rata atau mean sebesar 155,26, dengan standar deviasi $($ SDY $)=10,94$, median 158 , modus 159 , skor minimum 119, dan skor maksimumnya 173. Agar lebih jelas, maka dalam tabel berikut ini disajikan rekapitulasi angka-angka berdasarkan perhitungan statistik dasar. Sedangkan skor untuk variabel kurikulum $2013\left(\mathrm{X}_{1}\right)$ berada pada rentang 102 hingga 150. Berdasarkan data yang diperoleh dalam penelitian selanjutnya diolah secara statistik, dan diperoleh hasil, yakni jumlah keseluruhan $\left(\sum \mathrm{X}_{1}\right)=10.20131$, nilai ratarata (mean) sebesar 20133,30, dengan standar deviasi $\left(\mathrm{SDx}_{1}\right)=11,153$, median 20137,50, modus 159, skor minimum 102, dan skor maksimumnya 150. Agar lebih jelas, maka dalam tabel berikut ini disajikan rekapitulasi angka-angka berdasarkan perhitungan statistik dasar. 
Skor untuk variabel integritas $\left(\mathrm{X}_{2}\right)$ berada pada rentang 92hingga 145 . Berdasarkan data yang diperoleh dalam penelitian selanjutnya diolah secara statistik, dan diperoleh hasil, yakni jumlah keseluruhan $\left(\sum \mathrm{X}_{1}\right)=10.025$, nilai rata-rata (mean) sebesar 20131,90, dengan standar deviasi $\left(\mathrm{SDx}_{1}\right)=12,49$, median 20137, modus 20139, skor minimum 92, dan skor maksimumnya 145. Agar lebih jelas, maka dalam tabel berikut ini disajikan rekapitulasi angka-angka berdasarkan perhitungan statistik dasar. Uraian tersebut dapat direkapitulasi dalam tabel di bawah ini.

Tabel 1 Rekapitulasi Angka Statistik Dasar

\begin{tabular}{lccllllll}
\multicolumn{1}{c}{ Variabel } & $\mathrm{n}$ & \multicolumn{1}{c}{$\left(\sum \mathrm{Y}\right)$} & \multicolumn{1}{c}{ Mean } & $(\mathrm{SDY})$ & Median & Modus & $\begin{array}{c}\text { Skor } \\
\text { terendah }\end{array}$ & $\begin{array}{c}\text { Skor } \\
\text { tertinggi }\end{array}$ \\
\hline $\begin{array}{l}\text { Kinerja Guru } \\
\text { Kurikulum }\end{array}$ & 76 & 11.800 & 155,26 & 10,94 & 158 & 159 & 119 & 173 \\
2013 & 76 & 10.20131 & $\begin{array}{l}20133,3 \\
0\end{array}$ & 11,153 & $\begin{array}{l}20136,5 \\
0\end{array}$ & 159 & 102 & 150 \\
Integritas & 76 & 10.25 & $\begin{array}{l}20131,9 \\
0\end{array}$ & 12,49 & 20137 & 20139 & 92 & 145 \\
\hline
\end{tabular}

\section{b. Pengujian Persyaratan Analisis}

Uji normalitas merupakan hasil analisis program SPSS 25 dengan uji normalitas One-Sample KolmogorovSmirnov Test pada data skor variabel kinerja guru (Y), diperoleh nilai Asymp. Sig $(2$-tailed $)=0,200 ;$ skor variabel kurikulum 2013 (X1) diperoleh nilai Asymp. Sig (2-tailed)=0,200 dan skor variabel integritas (X2) diperoleh nilai Asymp. Sig (2-tailed)=0,060. Hal ini menunjukkan bahwa nilai Asymp. Sig (2tailed) dari ketiga variabel tersebut lebih besar dari harga Alpha $(\alpha)=0,05$. Dengan demikian, Ha diterima, dan itu berarti data berdistribusi normal yang tampak pada tabel di bawah ini.

Tabel 2 Rangkuman Hasil Perhitungan Uji Normalitas

\begin{tabular}{cccccc}
\hline No & Variabel & $\mathrm{N}$ & $\mathrm{L}_{\text {hitung }}$ & $\begin{array}{c}\text { Alfa } \\
(\alpha)\end{array}$ & Simpulan \\
\hline 1 & $\mathrm{X}_{1}$ & 76 & 0,200 & 0,05 & Normal \\
2 & $\mathrm{X}_{2}$ & 76 & 0,060 & 0,05 & Normal \\
3 & $\mathrm{Y}$ & 76 & 0,200 & 0,05 & Normal \\
\hline
\end{tabular}

Begitupun dengan hasil uji linieritas menunjukkan bahwa bahwa nilai signifikansi pada liniearity variabel kurikulum 2013 dengan variabel kinerja guru siswa sebesar 0,000. Karena nilai signifikansi $0,000 \leq$ dari $\alpha=0,05$, maka dapat disimpulkan bahwa terdapat hubungan yang linier antara variabel kurikulum $\left(\mathrm{X}_{1}\right)$ dengan variabel kinerja guru (Y). Dengan demikian, asumsi linieritas terpenuhi.

\section{c. Pengujian Hipotesis Penelitian}

Dalam praktik, analisis Regresi Sederhana (Simple Regression) digunakan untuk mengetahui sejauh mana nilai hubungan atau pengaruh antara variabel independen atau bebas $(\mathrm{X})$ dengan variabel dependen atau terikat (Y). Disebut regresi sederhana karena hanya ada satu variabel independen (X).

Tabel 3 Pengaruh Kurikulum $2013\left(X_{1}\right)$ terhadap Kinerja Guru (Y)

\begin{tabular}{|c|c|c|c|c|c|}
\hline \multirow{2}{*}{ Model } & \multicolumn{2}{|c|}{$\begin{array}{l}\text { Unstandardize } \\
\text { d Coefficients }\end{array}$} & $\begin{array}{c}\text { Standa } \\
\text { rdized } \\
\text { Coeffici } \\
\text { ents }\end{array}$ & \multirow{2}{*}{ t } & Sig. \\
\cline { 2 - 6 } & $\mathbf{B}$ & $\begin{array}{c}\text { Std. } \\
\text { Error }\end{array}$ & Beta & & \\
\hline \multirow{2}{*}{1} & $\begin{array}{c}\text { (Constant) } \\
\text { Kurikulum } \\
2013\end{array}$ & .62 .540 & 11.904 & & 6.178 .000 \\
\hline
\end{tabular}

a. Dependent Variable: Kinerja_Guru

Berdasarkan rumus persamaan regresi yaikni $\mathrm{Y}=\mathrm{a}+\mathrm{bX}_{1}$ maka perhitungan analisis regresi terhadap data skor variabel kinerja guru atas variabel kurikulum 2013 menghasilkan a (nilai konstanta) sebesar 73.540 dan b (koefisien regresi) sebesar 0,62013. Berdasarkan hasil tersebut maka pengaruh penggunaan pemahaman kurikulum $2013\left(\mathrm{X}_{1}\right)$ terhadap 
kinerja guru (Y) dapat dirumuskan menurut persamaan regresi, yakni: $\mathrm{Y}=$ $73,540+0,62013 X_{1}$. Hasil $Y$ adalah 74,153 . Dengan kata lain nilai 0,62013 mengandung arti bahwa setiap penambahan $\mathrm{X}$ satuan (1\%) pemahaman kurikulum 2013 (X2), maka kinerja guru (Y) akan meningkat sebesar 0,62013.

Oleh karena itu nilai $\mathrm{t}$ hitung $\left(\mathrm{t}_{\text {hit }}\right)$ adalah 6.889. Karena nilai t hitung antara $X_{1}$ (pemahaman kurikulum 2013) dengan $\mathrm{Y}$ (kinerja guru) yang diperoleh lebih besar dari nilai $\mathrm{t}$ tabel, yakni $\mathrm{t}_{\text {hitung }}=$ $6.889 \geq\left(\mathrm{t}_{\mathrm{tab}}\right)=1.992$. Dengan demikian, dapat dinyatakan bahwa koefisien regresi adalah berarti. Artinya bahwa pemahaman kurikulum 2013 berpengaruh terhadap kinerja guru. Selanjutnya dari uji Anova dihasilkan untuk nilai $\mathrm{F}$ hitung adalah 47.457 dengan tingkat signifikansi (angka probabilitas) sebesar 0,000. Karena angka probabilitas (Sig.) jauh lebih kecil dari alfa $(\alpha)$ : Sig. $=0,000 \leq$ dari $\alpha=0,05$, maka Ho ditolak dan $\mathrm{Ha}$ diterima. Artinya ada pengaruh antara pemahaman kurikulum $2013\left(X_{1}\right)$ dengan kinerja guru SD Katolik di Kota Manado (Y).

Tabel 4 Pengaruh Integritas $\left(\mathrm{X}_{2}\right)$ terhadap Kinerja Guru (Y)

\begin{tabular}{|c|c|c|c|c|c|c|}
\hline \multirow{3}{*}{\multicolumn{2}{|c|}{ Model }} & \multirow{2}{*}{\multicolumn{2}{|c|}{$\begin{array}{l}\text { Unstandardize } \\
\text { d Coefficients }\end{array}$}} & & \multirow{3}{*}{$\mathbf{t}$} & \multirow{3}{*}{ Sig. } \\
\hline & & & & \multirow{2}{*}{\begin{tabular}{|c}
$\begin{array}{c}\text { Stand } \\
\text { ardize } \\
\text { d }\end{array}$ \\
$\begin{array}{c}\text { Coeffi } \\
\text { cients }\end{array}$ \\
Beta
\end{tabular}} & & \\
\hline & & B & \begin{tabular}{|c|} 
Std. \\
Error
\end{tabular} & & & \\
\hline 1 & (Constant) & 122.244 & 12.924 & & 9.459 & .000 \\
\hline & Integritas & .250 & .098 & .286 & 2.566 & .012 \\
\hline
\end{tabular}

a. Dependent Variable: Kinerja_Guru

Hasil analisis regresi terhadap data skor variabel kinerja guru atas variabel integritas menghasilkan a (nilai konstanta) sebesar 122.244 dan b (koefisien regresi) sebesar 0,250. Artinya pengaruh penggunaan integritas $\left(\mathrm{X}_{1}\right)$ terhadap kinerja guru (Y) dapat dirumuskan menurut persamaan regresi, yakni: $\mathrm{Y}=$ $122.244+0,250 \mathrm{X}_{1}$. Hasil $\mathrm{Y}$ adalah 122.494. Dengan kata lain nilai 0,250 mengandung arti bahwa setiap penambahan $\mathrm{X}$ satuan (1\%) Integritas (X2), maka kinerja guru (Y) akan meningkat sebesar 0,250 . Besarnya nilai $\mathrm{t}$ hitung ( $\left.\mathrm{t}_{\text {hit }}\right)$ adalah 2.566 (lihat dalam tabel). Karena nilai $\mathrm{t}$ hitung antara $\mathrm{X}_{2}$ (integritas) dengan $\mathrm{Y}$ (kinerja guru) yang diperoleh lebih besar dari nilai t tabel, yakni $\mathrm{t}_{\text {hitung }}=2.566 \geq\left(\mathrm{t}_{\text {tab }}\right)=1.992$, maka Ho ditolak dan menerima Ha. Dengan demikian, dapat dinyatakan bahwa koefisien regresi adalah berarti. Artinya bahwa integritas berpengaruh terhadap kinerja guru.

Sedangkan uji Anova dihasilkan untuk nilai $\mathrm{F}$ hitung adalah 6.585 dengan tingkat signifikansi (angka probabilitas) sebesar 0,012. Karena angka probabilitas (Sig.) jauh lebih kecil dari alfa $(\alpha)$ : Sig. $=$ $0,012 \leq$ dari $\alpha=0,05$, maka Ho ditolak dan Ha diterima. Artinya ada pengaruh antara integritas $\left(\mathrm{X}_{2}\right)$ dengan kinerja guru SD Katolik di Kota Manado (Y).

Tabel 5 Pengaruh Pemahaman Kurikulum $2013\left(X_{1}\right)$ dan Integritas $\left(X_{2}\right)$ secara bersama-sama terhadap Kinerja Guru SD Katolik di Kota Manado (Y)

\begin{tabular}{|c|c|c|c|c|c|}
\hline \multirow[t]{2}{*}{ Model } & \multicolumn{2}{|c|}{$\begin{array}{l}\text { Unstandardi } \\
\text { zed } \\
\text { Coefficients }\end{array}$} & \multirow{2}{*}{\begin{tabular}{|l|}
$\begin{array}{l}\text { Standa } \\
\text { rdized } \\
\text { Coeffi } \\
\text { cients }\end{array}$ \\
Beta \\
\end{tabular}} & \multirow[t]{2}{*}{ 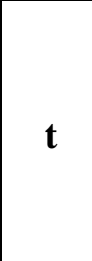 } & \multirow[t]{2}{*}{ Sig. } \\
\hline & B & \begin{tabular}{|c|} 
Std. \\
Error
\end{tabular} & & & \\
\hline (Constant) & 74.979 & \begin{tabular}{|l|}
2013. \\
20130 \\
\end{tabular} & & 5.711 & .000 \\
\hline $\begin{array}{l}1 \text { Kurikulum } \\
2013\end{array}$ & .627 & .103 & .639 & 6.094 & .000 \\
\hline Integritas & .025 & .092 & .028 & .268 & .790 \\
\hline
\end{tabular}

a. Dependent Variable: Kinerja_Guru

Rumus yang dipakai untuk melihat persamaan regresi ganda adalah $\mathrm{Y}=\mathrm{a}+$ $\mathrm{b}_{1} \mathrm{X}_{1}+\mathrm{b}_{2} \mathrm{X}_{2}$. Perhitungan analisis regresi berganda menghasilkan a (nilai konstanta) sebesar 74,979 $b_{1}$ sebesar 0.627 dan $b_{2}$ sebesar 0.025. Berdasarkan atas penafsiran tersebut maka pengaruh pemahaman kurikulum $2013\left(\mathrm{X}_{1}\right)$ dan integritas $\left(\mathrm{X}_{2}\right)$ secara bersama-sama terhadap kinerja guru SD Katolik di Kota Manado (Y) dapat dirumuskan menurut persamaan regresi 
berganda, yaitu: $\mathrm{Y}=74,979+0.627 \mathrm{X}_{1}+$ $0.025 \mathrm{X}_{2}$. Hasil Y adalah 75,631.

Selanjutnya persentase sumbangan pengaruh variabel pemahaman kurikuum 2013 dan integritas bersama-sama terhadap variabel kinerja guru SD Katolik di Kota Manado pada output SPSS 25 Model Summary dari hasil analisis regresi linier berganda di bawah ini.

Tabel 6 Model Summary

\begin{tabular}{|c|c|c|c|c|}
\hline \multirow{2}{*}{ Model } & \multirow{2}{*}{$\mathrm{R}$} & \multirow{2}{*}{ R Square } & \multicolumn{2}{|c|}{ Adjusted R Std. Error of the } \\
\hline & & & Square & Estimate \\
\hline 1 & $0.628^{\mathrm{a}}$ & 0.391 & 0.375 & 8.65048 \\
\hline
\end{tabular}

a. Predictors: (Constant), Kurikulum 2013, Integritas

Dari hasil analisis koefisien determinasi didapat nilai untuk Adjusted $R$. Square sebesar 0,375 atau 37,5\%. Hal ini menunjukan bahwa prosentase sumbangan pengaruh variabel pemahaman kurikulum 2013 dan integritas secara bersama-sama terhadap kinerja guru SD Katolik di Kota Manado sebesar 37,5 \%. Sedangkan sisanya dipengaruhi oleh variabel atau faktor lain yang tidak dimasukan dalam model penelitian ini.

Besarnya nilai $\mathrm{F}$ hitung $\left(\mathrm{F}_{\text {hit }}\right)$ adalah 23.467. Karena nilai $F$ hitung yang diperoleh lebih besar dari nilai $\mathrm{F}$ tabel, yakni $\left(\mathrm{F}_{\text {hit }}\right)=23.467 \geq\left(\mathrm{F}_{\mathrm{tab}}\right)=3.120$. Dengan demikian, dapat dinyatakan bahwa variabel pemahaman kurikulum 2013 dan integritas secara bersama-sama dapat mempengaruhi kinerja guru SD Katolik di Kota Manado. Sedangkan uji Anova dihasilkan untuk nilai $\mathrm{F}$ hitung sebesar 23.467 dengan tingkat signifikansi (angka probabilitas) sebesar 0,000. Karena angka probabilitas (Sig.) jauh lebih kecil atau kurang dari alfa $(\alpha)$ : Sig. $=0,000 \leq$ dari $\alpha$ $=0,05$, maka Ho ditolak dan Ha diterima. Dengan demikian, melalui analisis model regresi ganda ini dapat ditegaskan bahwa ada pengaruh yang signifikan antara pemahaman kurikulum 2013 dan integritas secara bersama-sama terhadap kinerja guru SD Katolik di Kota Manado.

\section{Pembahasan}

1. Pengaruh Pemahaman Kurikulum 2013 Terhadap Kinerja Guru SD Katolik Di Kota Manado

Berdasarkan uji hipotesis yang sudah dipaparkan sebelumnya dapat dibuktikan bahwa tingkat pemahaman kurikulum 2013 sangat mempengaruhi kinerja guru SD Katolik di Kota Manado. Hasil penelitian ini hendak menegaskan bahwa apabila guru SD yang memiliki pemahaman yang baik tentang kurikulum 2013 baik dalam aspek perangkat pembelajaran kurikulum 2013, perencanaan, pelaksanaan, strategi, sumber belajar, maupun proses evaluasi, kinerja guru-guru SD akan semakin meningkat pula. Kenyataan tersebut sesuai dengan hasil penelitian yang dilaksanakan pada guru-guru Sekolah Dasar Katolik di Kota Manado yakni pengaruh pemahaman kurikulum 2013 terhadap kinerja guruguru SD Katolik di Kota Manado sebesar $39,1 \%$. Persentasi ini diperoleh lewat hasil analisis program SPSS 25 yang terdapat dalam model summary bagian kolom $R$ Square.

Tabel 7 Model Summary

\begin{tabular}{lcccc}
\hline Model & $\mathrm{R}$ & $\begin{array}{c}\mathrm{R} \\
\text { Square }\end{array}$ & $\begin{array}{c}\text { Adjusted } \\
\text { R Square }\end{array}$ & $\begin{array}{c}\text { Std. } \\
\text { Error of } \\
\text { the } \\
\text { Estimate }\end{array}$ \\
\hline 1 & $0.625^{\mathrm{a}}$ & $\mathbf{0 . 3 9 1}$ & 0.382 & 8.59606 \\
\hline a. & Predictors: (Constant), Kurikulum_2013 \\
b. & Dependent Variable: Kinerja_Guru
\end{tabular}

Data tersebut juga menunjukkan bahwa ada faktor atau variabel lain sebesar $60,9 \%$ yakni $100 \%-39,1 \%$. yang ikut mempengaruhi kinerja guru-guru SD Katolik di Kota Manado yang tidak sempat dikaji dalam penelitian ini. Meskipun pengaruh pemahaman kurikulum 2013 terhadap kinerja guru tergolong rendah yakni $39,1 \%$.Ini berarti bahwa faktor atau variabel kurikulum 2013 bukan menjadi faktor penentu atau faktor dominan yang menentukan penilaian kualitas kinerja guru. Nampak jelas bahwa variabel lain tidak dijelaskan dalam penelitian ini justru 
memberikan pengaruh yang besar terhadap kinerja guru. Hasil penelitian ini juga sejalan dengan hasil penelitian dari Lodewyk (2015) yakni pengaruh kurikulum 2013 terhadap kinerja guru hanya sebesar 1,5\% dan 98,5 disebabkan oleh variabel lain di luar kurikulum 2013.

Hasil penelitian ini juga serupa dengan hasil penelitian dari Bintari, dkk (2016) di SD Pilotang Kabupaten Sleman yang menemukan bahwa (1) kinerja guru dalam perencanaan pembelajaran kurikulum 2013 sebesar 27,1\% kategori sangat baik dan sebesar $27,9 \%$ pada kategori baik; (2) kinerja guru dalam pelaksanaan pembelajaran kurikulum 2013 pada kategori sangat baik dengan persentase sebesar $63,4 \%$ dan kategori baik sebesar 36,6\%; (3) kinerja gur dalam penilaian pembelajaran kurikulum 2013 sebesar $49 \%$ kategori sangat baik, sebesar $50 \%$ pada kategori baik dan sebesar $1 \%$ pada kategori cukup. Artinya kinerja guru kelas di SD Pilatong Kurikulum 2013 Kabupaten Sleman berada pada kategori baik.

Berdasarkan hasil penelitian tersebut menjadi jelas bahwa peranan guru sangat menentukan keberhasilan kurikulum 2013. Oleh karena itu pemahaman guru terhadap kurikulum 2013 serta kreativitas guru sangat dibutuhkan agar kinerja dan kompetensi guru mengalami peningkatan dan sesuai dengan harapan pemerintah. Kualitas kinerja guru yang baik sangat dipengaruhi oleh tingkat pemahaman kurikulum 2013 meskipun besar pengaruh tergolong rendah. Dengan demikian, salah satu tugas utama guru SD adalah pengembangan pribadi lewat berbagai kegiatan sosialiasi, pelatihan dan seminar tentang kurikulum 2013.

\section{Pengaruh Integritas Terhadap Kinerja Guru SD Katolik di Kota Manado}

Hasil analisis penelitian menyatakan bahwa integritas berpengaruh terhadap kinerja guru SD Katolik di Kota Manado. Artinya semakin baik integritas sebagai seorang guru akan semakin meningkatkan kinerja guru di sekolah. Kenyataan ini sesuai dengan hasil penelitian lewat perhitungan koefisien determinasi yang menemukan bahwa pengaruh integritas terhadap kinerja guru sebesar 8,2\%. Persentasi tersebut diperoleh dari hasil analisis program SPSS 25 khususnya dalam kolom R Square.

Tabel 8 Model Summary

\begin{tabular}{ccccc}
\hline Model & R & R Square & $\begin{array}{c}\text { Adjuste } \\
\mathrm{d} \mathrm{R} \\
\text { Square }\end{array}$ & $\begin{array}{c}\text { Std. } \\
\text { Error of } \\
\text { the } \\
\text { Estimate }\end{array}$ \\
\hline 1 & $0.286^{\mathrm{a}}$ & $\mathbf{0 . 0 8 2}$ & 0.069 & 10.55317 \\
\hline
\end{tabular}

Predictors: (Constant), Integrtias

Dependent Variable: Kinerja_Guru

Berdasarkan hasil analisis tersebut ditemukan bahwa pengaruh integritas terhadap kinerja guru hanya sebesar $8,2 \%$ atau tidak memiliki pengaruh yang besar. Dengan kata lain faktor integritas bukan menjadi faktor atau variabel dominan, utama dan penentu peningkatan kinerja seorang guru. Faktor lain justru yang tidak diteliti dalam penelitian yang memiliki pengaruh yang besar terhadap kinerja guru. Dalam penelitian Malingkas (2018) menemukan bahwa pengaruh integritas terhadap kinerja kepala sekolah di tingkat SMA/SMK di Propinsi Sulawesi Utara sebesar $75,8 \%$.

Hasil penelitian tersebut memberikan sebuah penegasan bahwa kinerja seorang guru akan meningkatkan jika guru tersebut memiliki integritas yang baik. Guru yang memiliki integritas berarti ia memiliki komitmen, kejujuran, konsistensi dan dipercaya orang lain. Keutamaan seperti inilah yang membuat kinerja seorang guru bisa meningkat.

\section{Pengaruh Pemahaman Kurikulum 2013 dan Integritas Secara Bersama- sama Terhadap Kinerja Guru SD Katolik Di Kota Manado}

Berdasarkan uji hipotesis yang sudah dibuktikan bahwa pemahaman kurikulum 2013 dan integritas secara 
bersama-sama berpengaruh positif terhadap kinerja guru-guru SD Katolik di Kota Manado. Kinerja guru mengalami peningkatan jika guru memiliki pemahaman yang baik tentang kurikulum 2013 dan integritas yang baik. Kenyataan ini sesuai dengan bukti hasil analisis data perhitungan koefisien determinasi kolom Adjusted $R$ Square yang menjelaskan bahwa pengaruh pemahaman kurikulum 2013 dan integritas secara bersama-sama berpengaruh terhadap kinerja guru sebesar $37,5 \%$. Prosentasi ini nampak jelas dalam tabel di bawah ini.

Tabel 9 Model Summary

\begin{tabular}{ccccc}
\hline Model & $\mathrm{R}$ & $\begin{array}{c}\mathrm{R} \\
\text { Square }\end{array}$ & $\begin{array}{c}\text { Adjusted } \\
\text { R Square }\end{array}$ & $\begin{array}{c}\text { Std. Error } \\
\text { of the } \\
\text { Estimate }\end{array}$ \\
\hline 1 & $0.626^{\mathrm{a}}$ & 0.391 & $\mathbf{0 . 3 7 5}$ & 8.65048 \\
\hline a. & $\begin{array}{l}\text { Predictors: (Constant), Kurikulum_2013, } \\
\text { Integritas }\end{array}$ \\
b. & Dependent Variable: Kinerja-Guru
\end{tabular}

Dalam tabel tersebut nampak jelas bahwa secara bersama-sama pemahaman kurikulum 2013 dan integritas dapat memberikan pengaruh terhadap kinerja guru meskipun tingkat kualitas pengaruhnya tergolong rendah yakni $39.1 \%$. Sedangkan sisanya $62,5 \%$ disebabkan oleh variabel atau faktor lain selain daripada faktor kurikulum 2013 dan integritas. Dengan kata lain, pemahaman kurikulum 2013 dan integritas bukan faktor atau variabel yang paling dominan dan penentu peningkatan kinerja guru-guru SD Katolik di Kota Manado.

\section{KESIMPULAN}

Berdasarkan hasil pengolahan data dan analisis data, maka dapat disimpulkan: (1) Terdapat pengaruh positif faktor pemahaman kurikulum 2013 terhadap kinerja guru SD Katolik di Kota Manado. Walaupun tingkat pengaruh pemahaman kurikulum 2013 terhadap kinerja guru tergolong masih rendah yakni $39,1 \%$ dengan tingkat signifikansi $0,000 \leq$ dari $\alpha$ $=0,05$. Sedangkan hasil pengujian hipotesis variabel pengetahuan dengan $\mathrm{t}$ test menunjukkan bahwa ternyata yakni $\mathrm{t}_{\text {hitung }}=6.889 \geq\left(\mathrm{t}_{\mathrm{tab}}\right)=1.992$. Artinya bahwa pemahaman kurikulum 2013 berpengaruh terhadap kinerja guru; (2) Terdapat pengaruh integritas terhadap kinerja guru SD Katolik di Kota Manado. Kinerja guru juga bisa meningkat jika integritas guru semakin baik. Hal ini didukung dengan hasil prosentasi determinasi di mana $8,2 \%$ besarnya pengaruh integritas terhadap kinerja guru dengan tingkat signifikansi sebesar 0,012 $\leq$ dari $\alpha=0,05$. (3)Terdapat pula pengaruh pemahaman kurikulum 2013 dan integritas secara bersama-sama terhadap kinerja guru SD Katolik di Kota Manado yakni sebesar $37,5 \%$ dengan tingkat signifikansi $0,000 \leq$ dari $\alpha=0,05$.

Rekomendasi yang diberikan adalah: (1) Bagi dinas pendidikan kota Manado, agar lebih memperhatikan tingkat pemahaman para guru SD tentang kurikulum 2013 dan terus melakukan berbagai program pelatihan, sosialisasi dan pendalaman kompetensi bagi guru-guru khususnya kurikulum 2013. (2) Bagi sekolah, agar para kepala sekolah di tingkat sekolah dasar memberikan peluang kepada guru-guru untuk mengikuti berbagai kegiatan, pelatihan dan sosialiasi pengembangan dan peningkatan implementasi kurikulum 2013. (3) Bagi guru SD, untuk memberikan kesadaran kepada guru-guru SD tentang pentingnya kualitas integritas bagi seorang guru dalam rangka peningkatan kinerja di sekolah.

\section{DAFTAR PUSTAKA}

Armstrong, M. (2006). Performance management: Key Strategies and Practical Guidelines. London and Philadelphia: Kogan Page. Third Edition.

Ahmad, L. O. I. (2018). "Konsep Penilaian Kinerja Guru dan Faktor Yang Mempengaruhinya", dalam JURNAL IDAARAH, VOL. I, NO. 1, JUNI 2017.http://journal.uin- 
alauddin.ac.id/index.php/idaarah/ar ticle/download/420133/3818

Barnard, A., Schurink, W., \& Beer, M (2008). "A Conceptual Framework of Integrity" dalam SA Journal of Industrial Psychologgy, Vol. 34 No. pp.40-49

Bintari, H. R. (2016). "Kinerja Guru Kelas dalam Pelaksanaan Kurikulum 2013 di SD Piloting Kabupaten Sleman," dalam Jurnal Pendidikan Guru Sekolah Dasar Edisi 8 Tahun k-5 2016 http://journal.student.uny.ac.id/ojs/i ndex.php/pgsd/article/viewFile/201 320/1195

Koerselman, K. (2013). Incentive from Curriculum Tracking. Economic Education Review Journal. Elsevier. 32 (1). Pp. 140-150.

Haslina, Y., dan Usman, N. (2017). "Kinerja Guru dalam Implementasi Kurikulum 2013 pada SMA Negeri 5 Lhokseumawe," dalam Jurnal Magister Administrasi Pendidikan, Pascasarjana Universitas Syiah Kuala Volume 5, No. 4 November 2017, ISSN 2302-0156 pp. 211217.

http://www.jurnal.unsyiah.ac.id/JA P/article/view/9359

Lodewyk, P. (2015). "Pengaruh Kurikulum 2013 terhadap Kinerja Guru Sekolah Dasar di Kota Palembang," Skripsi Program Studi Manajemen Fakultas Ekonomi Universitas IBA Palembang.

Malingkas, M. (2018). "The Effects of Servant Leader and Integrity on Principals' Performance of Catholic Senior High Schools in North Sulawesi Indonesia”. Journal of International Education and Leadership, Vol. 8, No. 1 Spring 2018 ISSN 2161-7252. http://www.jielusa.org/wpcontent/uploads/2018/02/Malingka s19Spring2018.pdf
Nurdin, S. dan Masyirudin, U. (2002). Guru Profesional dan implementasi Kurkulum. Jakarta: Ciputat Pers

Rasto, K. (2016). "Kompetensi dan Kinerja Guru Berdasarkan Sertifikasi Profesi”, dalam Jurnal pendidikan manajemen perkantoran Volume 1, nomor 1, Agustus 2016 halaman $64-74$. http://ejournal.upi.edu/index.php/jp manper/article/download/3269/231 9

Supardi. (2013). Kinerja Guru. Jakarta: Raja Grafindo Persada. 